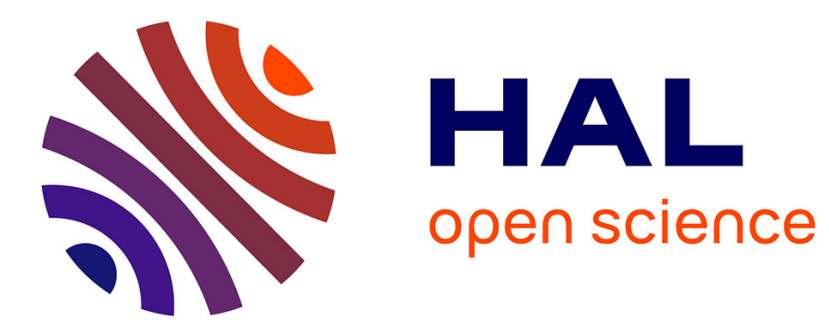

\title{
Programming, optimal pricing and partnership contract for infrastructures in PPPs
}

\author{
Alain Bonnafous
}

\section{To cite this version:}

Alain Bonnafous. Programming, optimal pricing and partnership contract for infrastructures in PPPs. Research in Transportation Economics, 2010, 30 (1), pp. 15-22. 10.1016/j.retrec.2010.10.003 . halshs-00578246

\section{HAL Id: halshs-00578246 \\ https://shs.hal.science/halshs-00578246}

Submitted on 24 Mar 2011

HAL is a multi-disciplinary open access archive for the deposit and dissemination of scientific research documents, whether they are published or not. The documents may come from teaching and research institutions in France or abroad, or from public or private research centers.
L'archive ouverte pluridisciplinaire HAL, est destinée au dépôt et à la diffusion de documents scientifiques de niveau recherche, publiés ou non, émanant des établissements d'enseignement et de recherche français ou étrangers, des laboratoires publics ou privés. 
Programming, optimal pricing and partnership contract for infrastructures in PPPs Bonnafous A. Research in Transportation Economics 30, 1 (2010) pp. 15-22 - http://halshs.archives-ouvertes.fr/halshs-00578246/fr/ DOI : 10.1016/j.retrec.2010.10.003

\title{
PROGRAMMING, OPTIMAL PRICING AND PARTNERSHIP CONTRACT
}

\section{FOR INFRASTRUCTURES IN PPPS}

\section{Alain Bonnafous ${ }^{1}$}

\begin{abstract}
The development of various forms of public-private partnerships for the financing, building and operating of public infrastructure has not fundamentally altered the economic calculations involved. This chapter examines to what extent it is necessary, however, to change the way that government uses socio-economic and financial evaluations, whether to optimise investment programming or pricing. Ensuring a coherent match between these two types of optimisation can provide a principle for determining the optimal programming price.
\end{abstract}

We begin by showing that when projects are financed by both users (toll revenues) and taxpayers (subsidies), it is socially beneficial to plan these investments on the basis of the net present value (NPV) provided by each unit of public money invested. This NPV/subsidy ratio must obviously be higher than the public-funding scarcity coefficient or else the investment would destroy more wealth than it would produce.

One of the ways of improving this ratio is also to optimise the toll level, since increasing it can lower the subsidy but has an adverse impact on the user surplus, it is essential to set the optimal toll.

In the case of an approved project considered in isolation, we show that the optimal toll depends upon the public-funding scarcity coefficient. If there is no scarcity, the optimal toll is zero. As public funding becomes scarcer, the optimal toll draws closer to the toll that optimises revenue.

In the case of a programme of several projects subject to budget constraint, we show that the optimal toll no longer depends upon the public-funding scarcity coefficient and that there are several scenarios depending on the relative values of the maximum revenue and the total cost of the project:

when, whatever the toll, revenue can no longer cover over half of the cost, it is socially beneficial to choose not to levy any toll;

- $\quad$ when there is a toll that covers the total cost, the operator may be left free to set it at the level he sees fit, with the issue of how the profits are to be shared between the franchisee and the franchisor being settled separately;

- $\quad$ when the maximum revenue of the project falls between half and all of the total cost, the value of the toll that maximises the welfare function is lower than the

\footnotetext{
${ }^{1}$ Emeritus Professor of the University of Lyon, Laboratoire d'Economie des Transports.
} 
revenue-maximising toll and must therefore be set for the private operator by government.

Thus, the partnership contract must be given a different content in these three cases of optimal pricing.

\section{Preamble}

Most of the theoretical studies devoted to optimising public investment programming and infrastructure pricing have, since the work of Jules Dupuit (1844), focused on the salient issues of the transport sector, even though this work was relevant to all sorts of public infrastructure. The analysis presented in this paper deals with transport economics, but in line with this tradition, is also applicable to any field in which public funding is combined with commercial revenue. For example, the question of determining how the financing of an opera should be shared between taxpayers and opera-goers raises the same type of issues as the optimal combination of tolls and subsidies for financing a motorway project. This report will be focused on these issues. We shall see that certain precautions are called for in investment programming together with some new thinking on pricing principles.

\section{Introduction}

The vigorous development of various forms of public-private partnerships in the field of public infrastructure investment and operation has renewed interest in theoretical thinking about what had been considered as methodological givens in the field of the public economy. By definition, a PPP system must combine the rationales of government and of a private operator. The latter's objective function is the profit of the operation, a profit that is obviously discounted and if appropriate enriched by taking uncertainty into account. The government's objective function is the discounted variation in social welfare that takes into account, in addition to the operator's profit, factors such as public spending, user surpluses and environmental impact. Many factors can affect both these objective functions differently, in particular infrastructure pricing, which is in principle not the same depending on whether it optimises the operator's profits or social welfare.

The questions raised by these renewed arrangements between the public sphere and private partners have mainly concerned one of the most fertile fields of recent decades, i.e. the theory of incentives. The studies in this field have focused most especially on the specific nature of a partnership contract and thus the principal/agent relationship, following the ground-breaking work of Jean-Jacques Lafont and Jean Tirolles (1993). Many particularly useful articles on PPPs, including the most recent ones, have continued work within this theoretical tradition (such as Hart, 2003 and Desrieux, 2006). However, little work has been done on the contributions and changes to the public economy implied by this new development.

In the specific case of France, a second event renewed the problem of evaluation, and was triggered by the conclusions of the Working Group of the French Planning Authority chaired by Daniel Lebègue (Commissariat Général du Plan, 2005). Its mission was to think about the relevant value of what is conventionally known in France as "the discount rate of the Plan", which had been set at $8 \%$ for some twenty years. In addition to the strong theoretical reasons 
supporting a lower rate (Gollier, 2002), the fact of the matter is that this $8 \%$ rate was ill suited to taking environmental externalities into account effectively in the economic calculation, since it resulted in giving a very low weighting to the distant future. For example, a value considered over a 30 year time horizon is virtually divided by 10 if it is discounted at an $8 \%$ rate. It is only divided by roughly three with a discount rate reduced to $4 \%$, i.e. the rate that was recommended by the Lebègue Report ${ }^{2}$ and that was used in official instructions (Ministry for the Environment, 2005). In this way, France aligned itself more closely with the rates used in EU countries, such as $3 \%$ in Germany.

However, this recommendation had the effect of multiplying the number of new projects considered to be cost-effective, since their net present value (NPV) now became positive if their socio-economic internal rate of return (IRR) fell between $4 \%$ and the former rate of $8 \%$. It also generated a growing number of "potential" projects, i.e. for which the optimal implementation date had already passed since their immediate rate of return was higher than the official discount rate. This made it more urgent to rank the potential projects and programme them in an order that would maximise the welfare function. This optimisation not only implies the order of implementation of projects, but also the subsidies that each of them may require and, therefore, the constraint in terms of available public funding. The aim of this paper is to point out some recent results on this optimisation subject to a public funding constraint and to formalise the role of pricing when these projects involve a public-private partnership or, more generally, joint financing by users and taxpayers.

\section{Summary of some recent episodes on the ranking of potential projects}

The prior work that we must refer to at this point in our presentation has mainly dealt with the evaluation and programming of transport investments. To place this work in context, we should point out the what the ordinary practice has been in this field (particularly in France), both for projects financed through public funding, such as roads or motorways not operated under a franchise, and for projects financed through their revenues, such as toll motorways. In the first case, the concept of financial return was irrelevant since the projects did not generate any commercial revenue. In the second case, the financial rates of return were calculated solely to ensure that the projects could be self-financing and not to rank them, for the aim was not to optimise the profit of the project developer, whether this was a public establishment such as the national rail transport company (SNCF) or a semi-public company holding a motorway franchise. Thus, whether or not a toll was to be charged, investment programming was long based solely on the socio-economic evaluation of the investments.

As an initial approximation, the socio-economic rate of return (ERR) was used to rank the potential projects, i.e. those whose net present value (NPV) was positive and whose optimal date of implementation had passed. When a project designated as having priority (because its ERR was very high) had a financial internal rate of return (IRR) that was insufficient to ensure its selffinancing, additional funding was required, which might be a subsidy, as in the case of the TGV high-speed trains built after the South-East TGV line, or a disguised subsidy, as in the so-called system of "adossement" long used for toll motorways in France. This consisted of commissioning the franchisee of a motorway network to construct and operate a complementary segment that was financed partly by the cash-flows from older segments and that included, if necessary, a lengthening of their franchise.

2. More specifically, the report recommends a decrease of the (real) discount rate to $4 \%$ and even a gradual lowering of the rate to $2 \%$ for time horizons longer than 30 years (Commissariat Général du Plan, 2005). 
This system recently disappeared, around the turn of the last century, as it was incompatible with European legislation, but also because of the growing number of projects that do not have a sufficient IRR to be able to finance them without subsidies. All this has enhanced the rationale of joint financing by taxpayers and users and, consequently, public-private partnership in the broad sense, rather than in the restrictive sense of a partnership contract. For example, the franchise for which competition is open for the infrastructure of the South Atlantic Europe (SEA) TGV line is obviously a PPP. However, this posed the problem of the optimal programming of investments in new terms that were not immediately recognised.

This problem can be stated very simply: it consists of determining, among the potential projects, those that will be selected and their optimal implementation date so that, subject to the available public budget constraint, the net present value (NPV) of the programme thus established will be maximised.

In this programming problem, the subsidy rate obviously plays a major role in formulating the budget constraint. For each project, this rate is simultaneously a function of the financial rate of return that an investor may require, of the project's intrinsic rate of return and, thus, of its economic characteristics. A formulation of this function has been proposed (Bonnafous, 2002), which has made it possible to establish the equivalent of numerical tables or counting frames as represented on Figure 1. To facilitate the analysis, we suppose a standard case in which the capital cost is incurred at an annual rate $c$ between the dates $t=-d$ and $t=0$. When the project comes into use at time 0 , the annual profit rate (revenues less operating and other ongoing costs) takes the form $(a+b . t)$.

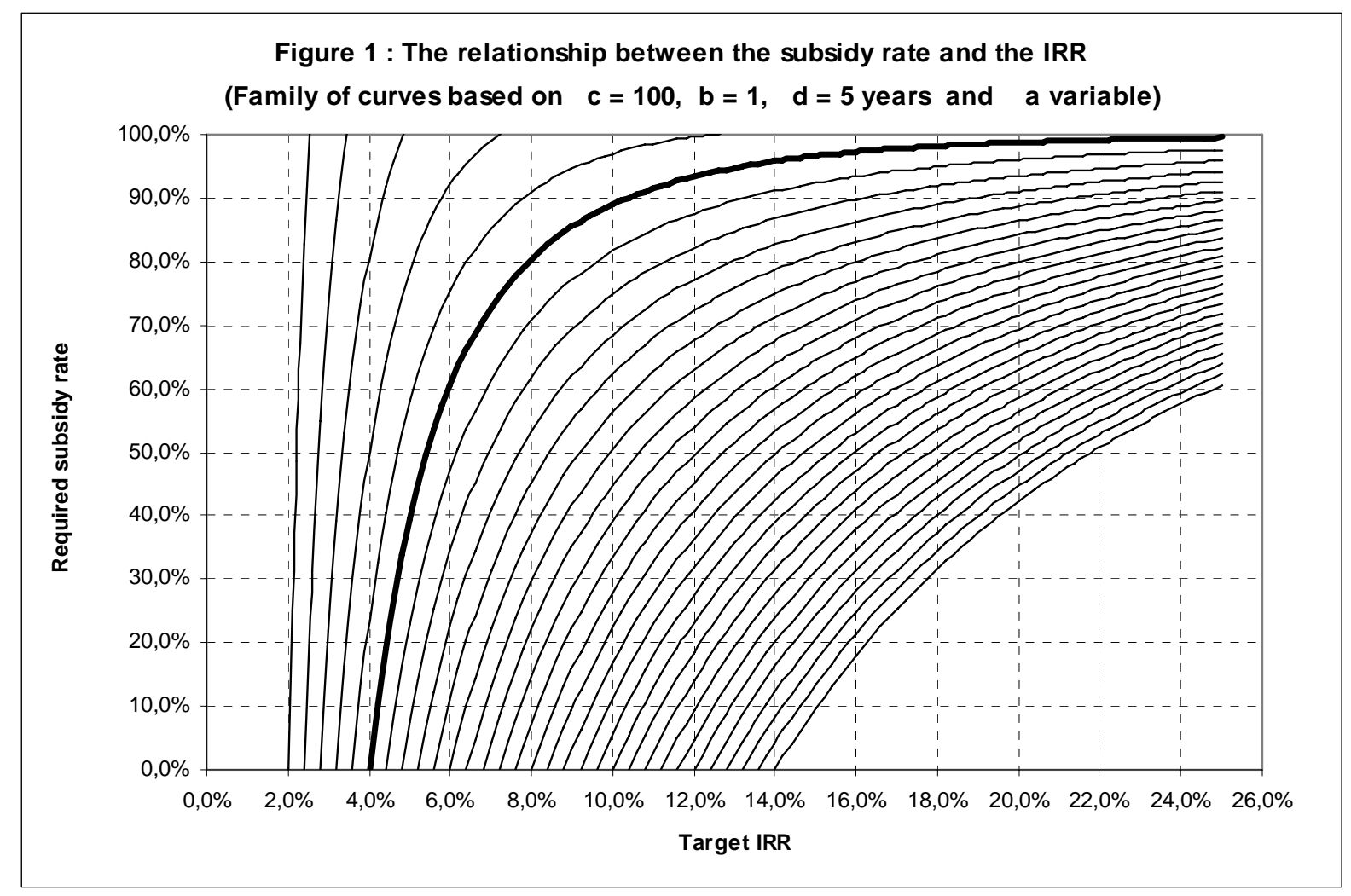

The family of curves shown in Figure 1 is drawn for the numerical case given by $c=100, b=$ $1, d=5$ together with alternative values of a chosen so that as a increases from one value to the 
next, the IRR increases by 0.4 percentage points. Thus, each curve corresponds to a particular value for $a$, and shows how the required subsidy rate increases as we increase the IRR from its intrinsic value (without subsidy) to the target value required by the operator.

For example, for an investment characterised by a such standard chronology of the costs and benefits that it generates and by an intrinsic IRR of $4 \%$, a subsidy rate of $80 \%$ proves to be necessary to "raise" this financial rate of return to $8 \%$. This rate of $8 \%$ corresponds to the order of magnitude of IRR required today by an operator such as Réseau Ferré de France if its earnings are not to suffer.

The use of this subsidy rate function has facilitated several exercises, which consist of comparing various investment programmes subject to the same public funding constraint. These exercises were conducted (Bonnafous and Jensen, 2005) for a same set of 17 "potential" projects being considered in the early 1990s. The first consists of testing several orders of project implementation by saturating the budget constraint each year: the decreasing order of ERRs, then the decreasing order of the IRRs and lastly random orders (alphabetical and reverse alphabetical). The objective function, i.e. the net present value of the programme, is obviously calculated for each case. The exercise was conducted for different levels of budget constraint.

An initial trivial result showed that the random orders generate the lowest overall NPVs, whether the public funding constraint is loose or tight. Another less predictable result showed that a programme of project implementation by decreasing order of financial rates of return (IRRs) generated a higher overall NPV than the programme ranked by decreasing socio-economic rates of return (ERRs). In addition, the tighter the budget constraint, the more clearly the social return of the project programme - in the sense of its socio-economic NPV (or welfare gain) - is improved by the IRR criterion (a result that is obviously important for developing countries for which the public funding constraint is very active).

The explanation for this is simple: the projects ranked according to the criterion of decreasing IRR are implemented at a faster pace, as their strong financial rate of return implies lower subsidies. For an equivalent public expenditure, the output of socio-economic NPV is therefore higher.

The second exercise confirmed and enriched the preceding one. It dealt with the same 17 projects which can give rise to 17 ! possible permutations (roughly $10^{34}$ ), which requires one of the combinatorial exploration algorithms (such as the simulated annealing method) used by the experimental sciences in dealing with such complexity. The programmes explored saturate, of course, the public funding constraint.

These simulations have confirmed that the tighter the budget constraint, the greater the programme's gain in overall socio-economic NPV with the decreasing order of IRRs in relation to the decreasing order of ERRs. However, first and foremost, they have confirmed for us that, for standard observations of costs and benefits, the order of the ratio of NPV/public euro invested generates an even higher gain in social return and that it is in fact the criterion that designates the optimal programme, in the sense of the numerical optimisation algorithm. 


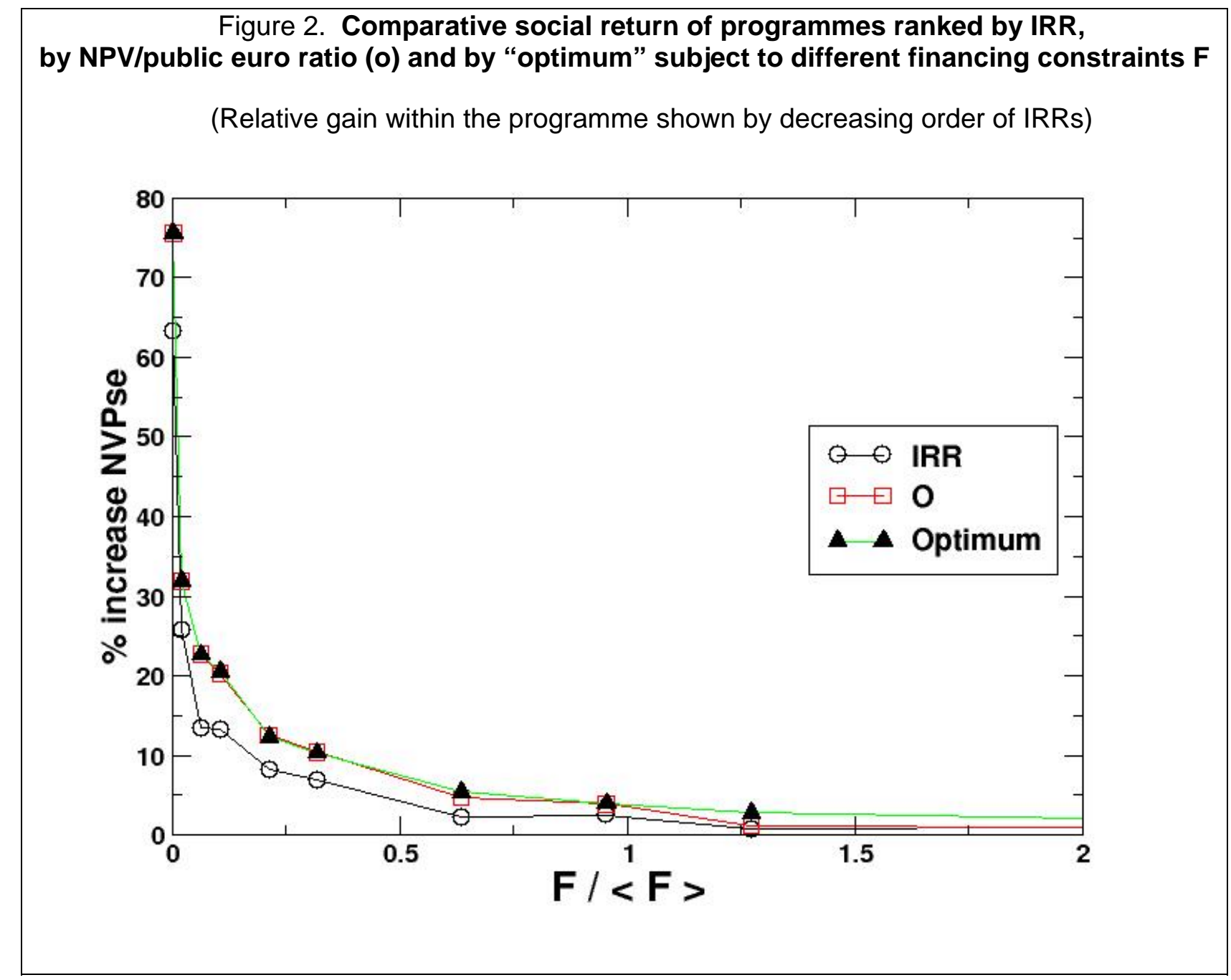

(Source: Bonnafous and Jensen, 2005)

Lastly, a formalised demonstration of the problem has been proposed (Roy, 2005), which shows, under relatively weak conditions ${ }^{3}$, that the ratio of NPV/public euro invested is indeed the criterion for ranking projects that maximises overall social welfare. This demonstration needs to be discussed here, for it makes it possible to define rigorously the concept of public-funding scarcity coefficient that we will need to address the optimal pricing.

\section{Programming problem and public-funding scarcity coefficient}

The theoretical model established by William Roy is general and easy to interpret as it is formally close to the programme of the consumer for discrete goods. Let us assume that the decision-maker has to choose among $n$ projects $i$, characterised by their net present value $\Delta U_{i}$ and their need for subsidies $S u b_{i}$, with $\Delta U_{i}>0$ and $S u b_{i}>0 \quad \forall i=1, \ldots, n$. The pricing is for the time being considered as a given, set by an exogenous rule. We then take, as the objective function of the community, the overall productivity surplus $W$ generated by all the projects, subject to the budget constraint $B$ capping public spending. The optimisation programme can then be written as follows: 


$$
\begin{array}{ll}
\operatorname{Max}_{x} & W(x)=\sum_{i=1}^{n} x_{i} \Delta U_{i} \\
\text { s.c. } & \left\{\begin{array}{l}
B-\sum_{i=1}^{n} x_{i} S u b_{i} \geq 0 \\
x_{i} \geq 0, \quad \forall i=1, \ldots, n \\
1-x_{i} \geq 0, \quad \forall i=1, \ldots, n
\end{array}\right.
\end{array}
$$

The parameters $x_{i}$ are continuous variables, which have a zero value when the project is not implemented and equal to one when the project implemented fully. We shall assume that it is possible to implement partially project $k$, with parameter $x_{k}$ then ranging between 0 and 1 . Obviously, possibility of implementing partially a project $k$, while implying proportionally its characteristics $\left(\Delta U_{k}\right.$ and $\left.S u b_{k}\right)$, is a purely theoretical working hypothesis.

The solution vector $x^{*}$ is therefore constituted by a value set 1 (projects to be implemented), a value set 0 (projects not to be implemented), and a value ranging between 0 and 1 for the "borderline" project $k$ (which is very likely not to be completed if the constraint is totally inflexible). Assuming that the projects are ranked by their implementation priority, we can write this solution vector as:

$$
x^{*}=(\underbrace{1, \ldots \ldots . .1}_{\text {projects accepted }}, x_{k}, \underbrace{0, \ldots \ldots ., 0}_{\text {projects rejected }})
$$

The Lagrangian of the optimisation problem is written as follows:

$$
L\left(x_{1}, \ldots, x_{n}, \varphi, \alpha_{1}, \ldots, \alpha_{n}, \beta_{1}, \ldots, \beta_{n}\right)=\sum_{i=1}^{n} x_{i} \Delta U_{i}+\varphi\left(B-\sum_{i=1}^{n} x_{i} \operatorname{Sub} b_{i}\right)+\sum_{i=1}^{n} \alpha_{i} x_{i}+\sum_{i=1}^{n} \beta_{i}\left(1-x_{i}\right)
$$

The Kuhn and Tucker conditions imply in particular that at optimum:

- $\Delta U_{i}-\varphi \cdot S u b_{i}+\alpha_{i}-\beta_{i}=0, \forall \mathrm{i}=1, \ldots, \mathrm{n}$

- $\varphi\left(B-\sum_{i=1}^{n} x_{i} S u b_{i}\right)=0$

- $\quad \alpha_{i} x_{i}=0$ et $\beta_{i}\left(1-x_{i}\right)=0, \forall \mathrm{i}=1, \ldots, \mathrm{n}$

The economic interpretation of this optimisation is simple: $\varphi$ is the variation in the community surplus generated by a loosening of the public-funding availability constraint. Being equal to the maximum surplus amount that the community can hope to obtain from an additional budgetary unit, $\varphi$ represents the opportunity cost of public funds. It is important to distinguish this opportunity cost from the shadow cost of public funds, which results from the costs of collecting taxes and the price distortions associated with raising taxes by an additional unit. It is therefore not by chance that we are calling $\varphi$ a scarcity coefficient: dual value of the budget constraint, it really is the signal "price" of the scarcity of public funding. 
For the projects accepted (indexed $\jmath$ ), the Kuhn and Tucker conditions imply:

- That the constraint " $x_{i} \geq 0$ " is not saturated, and therefore $\alpha_{j}=0$

- That the constraint " $1-x_{i} \geq 0$ " is saturated, and therefore $\beta_{j}>0$

Whence $\Delta U_{j}-\varphi S u b_{j}>0 \Leftrightarrow \frac{\Delta U_{j}}{S u b_{j}}>\varphi$

The set of acceptable projects is therefore composed of those having a $\Delta U_{j} / S u b_{j}$ ratio higher than the opportunity cost of public funds $\varphi$. For the projects rejected or postponed (indexed $I$ ), the optimisation conditions imply:

- That the constraint " $x_{i} \geq 0$ " is saturated, and therefore $\alpha_{l}>0$

- That the constraint " $1-x_{i} \geq 0$ " is not saturated, and therefore $\beta_{l}=0$

Whence $\Delta U_{l}-\varphi \cdot S u b_{l}>0 \Leftrightarrow \frac{\Delta U_{l}}{S u b_{l}}<\varphi$

In all, the projects indexed $j$ selected and the projects indexed I not selected confirm the fundamental relationship:

$$
\frac{\Delta U_{j}}{S u b_{j}}>\varphi>\frac{\Delta U_{l}}{S u b_{l}}
$$

The projects accepted must always have a $\Delta U / S u b$ ratio higher than that of the projects rejected. This coincides with the result of the previous paragraph, for preference is given to the projects producing the greatest net present value per public euro invested $\left(\Delta U_{i} / S u b_{i}\right)$.

By varying $\varphi$ (loosening or tightening the budget constraint), a complete ranking of priorities can be constructed, which will be based on the criterion $\Delta U / S u b$. Thus, to optimise the overall surplus of a programme of projects subject to a budget constraint, including if the decision-maker does not know $\varphi$, the projects selected first must be those with the highest "social welfare per public euro invested".

We should point out that this criterion is fully consistent with the "demonstration" by numerical simulation presented in the preceding paragraph, and also with the standard results of microeconomics. Its significance is directly related to consumer theory, for when a consumer's utility optimisation is at equilibrium, he equalises all relationships between marginal utility and price. In our case, the consumer becomes the community, the "Little Father of the People" in the meaning of Jacques Lesourne (1972), in his role of purchasing public goods. This modelling, which William Roy has generalised in a dynamic configuration, i.e. of successive periods, simply bypasses the difficulty constituted by the indivisibility of the investments considered.

It also generates a concept, the public-funding scarcity coefficient, which we will need later in our discussion. Lastly, it suggests to us that the hypothesis of exogenous or predetermined 
pricing should be excluded, as it is clear that the $\Delta U / S u b$ ratio is dependent on the price charged to users since this has an impact both on the variation in social welfare of a project (in the sense of its NPV) and on the level of subsidy required.

\section{Simplified approach to the problem of the optimal pricing of financing}

Infrastructure pricing is a very old issue. An abundant literature has studied this subject, particularly in the fields of transport and energy economics, and has led to a recommended approach on which there is a near consensus. It can be summarised briefly as follows: in a shortterm perspective, marginal social cost pricing leads, under ultimately predictable assumptions, to a first-order optimum. When demand is subject to a capacity constraint, the need to invest to limit congestion and its social costs generates long-term incremental and marginal costs leading to higher charges, but which are not always sufficient to cover the average costs if the fixed costs are large, which is a frequent characteristic of network activities.

This being the case, this long-run marginal social cost pricing must be modified so as to increase the revenue generated. The modification that deviates the least from the first-order optimum is the one that deforms the least the structure of demand. The result, known as Ramsey-Boiteux, then consists of increasing the charges for a demand segment in inverse proportion to the price elasticity of demand in that segment (Boiteux, 1956). This is therefore a second-order optimum in the sense that the welfare function is optimised subject to a constraint on the capacity of deficit financing by public funds.

We shall adopt this perspective by considering that, in the welfare function, public funds are to be assigned a scarcity coefficient that we shall call $\varphi$. The precise definition of $\varphi$ and its theoretical implications have been specified in the preceding paragraph. The issue of the relevant estimate of $\varphi$ will not be addressed here, either through an approach in terms of the opportunity cost of public funds (Ponti and Zecca, 2007) or an implicit scarcity coefficient of government revealed by its decisions regarding tolls (Abraham, 2008). We shall confine ourselves below to varying $\varphi$ in a range of reasonable values.

We shall also assume that the non-monetary components of the marginal social cost (including the environmental components) are covered by taxes collected by government. An example, in the field of transport, would be the domestic tax on petroleum products and the assumption that the corresponding revenues are not allocated to the transport system beyond covering the marginal user cost. This relieves us of addressing certain highly topical issues such as the allocation of the various taxes paid by users (De Palma et alii, 2007).

Consequently, the share of financing provided by the users of a motorway can, in this analysis, only be derived from toll revenues. This working hypothesis has the result of neglecting not only the issue of environmental costs, assumed to be suitably internalised by taxes, but also the issue of congestion tolls. This latter restriction is less problematic given that in many countries today, including France, the new infrastructure franchised or partially financed by tolls rarely involves congested routes. The problem of the optimal toll is therefore reduced to a financing issue or, if one prefers, to the sole issue of the trade-off between paying users and taxpayers.

With this assumed equilibrium between external costs and taxes, the evaluation of a project can be formulated in a very simplified way: the variation in social welfare related to the project $(\Delta U)$ is then only a function of the discounted subsidy (which can be defined as the difference 
between the discounted investment and operating costs $C$ and the discounted revenue of the project $R$ ) and the discounted user surplus $S$. This function is then written as:

$$
\Delta U=-\varphi \cdot S u b+S=\varphi(R-C)+S
$$

Unless otherwise indicated, we shall assume that the revenue is always lower than the costs and that there is therefore always a need for subsidies. This is the case for the vast majority of the current motorway and rail projects in most countries.

As the discounting calculations are in constant prices, we shall assume that the toll $p$ remains unchanged over the discounting period and that the discounted demand $d$ can be expressed as a linear function of $p$, as follows:

$$
d=d_{0}-\beta \cdot p
$$

The result is a discounted revenue:

$$
R=d_{0} \cdot p-\beta \cdot p^{2}
$$

The discounted user surplus, for a price level $p$, is expressed as follows:

$$
S=\frac{\beta}{2}\left(\frac{d_{0}}{\beta}-p\right)^{2}
$$

The last three equations are shown in Figure 3 below.

Some characteristic values of this highly stylised economy can be identified here: the "maximum" toll at which demand vanishes and which is equal to $d_{0} / \beta$, or the revenue-maximising toll which is half of the latter and where the value of this maximum revenue is $d_{0}^{2} / 4 \beta$. 


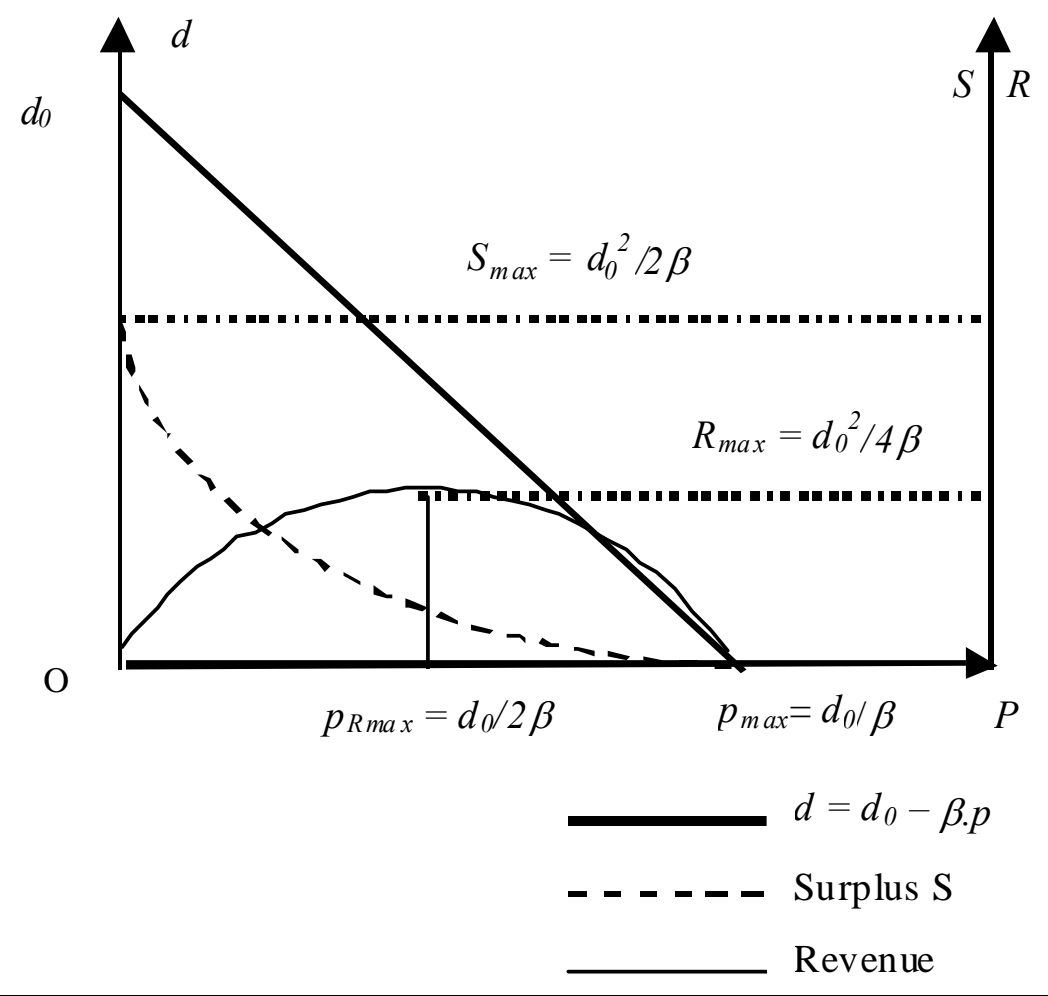

Equations (3) and (4) enable to show explicitly the social welfare variation defined by equation (1) which is a second-order polynomial function of the toll:

$$
\Delta U=-\varphi \cdot C+\frac{d_{0}{ }^{2}}{2 \beta}+(\varphi-1) \cdot d_{0} \cdot p+\beta \cdot\left(\frac{1}{2}-\varphi\right) \cdot p^{2}
$$

The welfare gain from the project will thus be greatest for a toll $p_{U \max }$ that maximises this function and cancels out its derivative:

$$
(\Delta U)^{\prime}=(\varphi-1) \cdot d_{0}+\beta \cdot(1-2 \varphi) \cdot p
$$

Let:

$$
p_{U \max }=\frac{\varphi-1}{2 \varphi-1} \times \frac{d_{0}}{\beta}
$$

This toll that maximises the welfare from the project is therefore zero when $\varphi$ equals 1 and from 0 to $d_{0} / 2 \beta$ when $\varphi$ is greater than 1 . Both cases are shown in Figure 3, where the function $\Delta U$ has been deliberately translated, so that the function $(\Delta U+C)$ is shown as ordinate. This has the advantage of better reflecting the weight of revenue and surplus in the composition of $\Delta U$ and reminding us that for $\varphi=1$, any increase in the toll has an adverse impact on $\Delta U$. This is the 
mechanism clearly identified by Jules Dupuit: the decrease in surplus resulting from this increase (which he called "welfare loss") is always greater than the increase in revenue. According to our hypothesis that the demand function is linear and, in the case of an identical toll for all users, the maximum revenue equal to $d_{0}^{2} / 4 \beta$ is only half the maximum surplus accruing to users when the toll is zero. We know that only with entirely discriminatory pricing can the full user surplus be internalized.

\section{Figure 4. Social welfare variation and the public-funding scarcity coefficient}

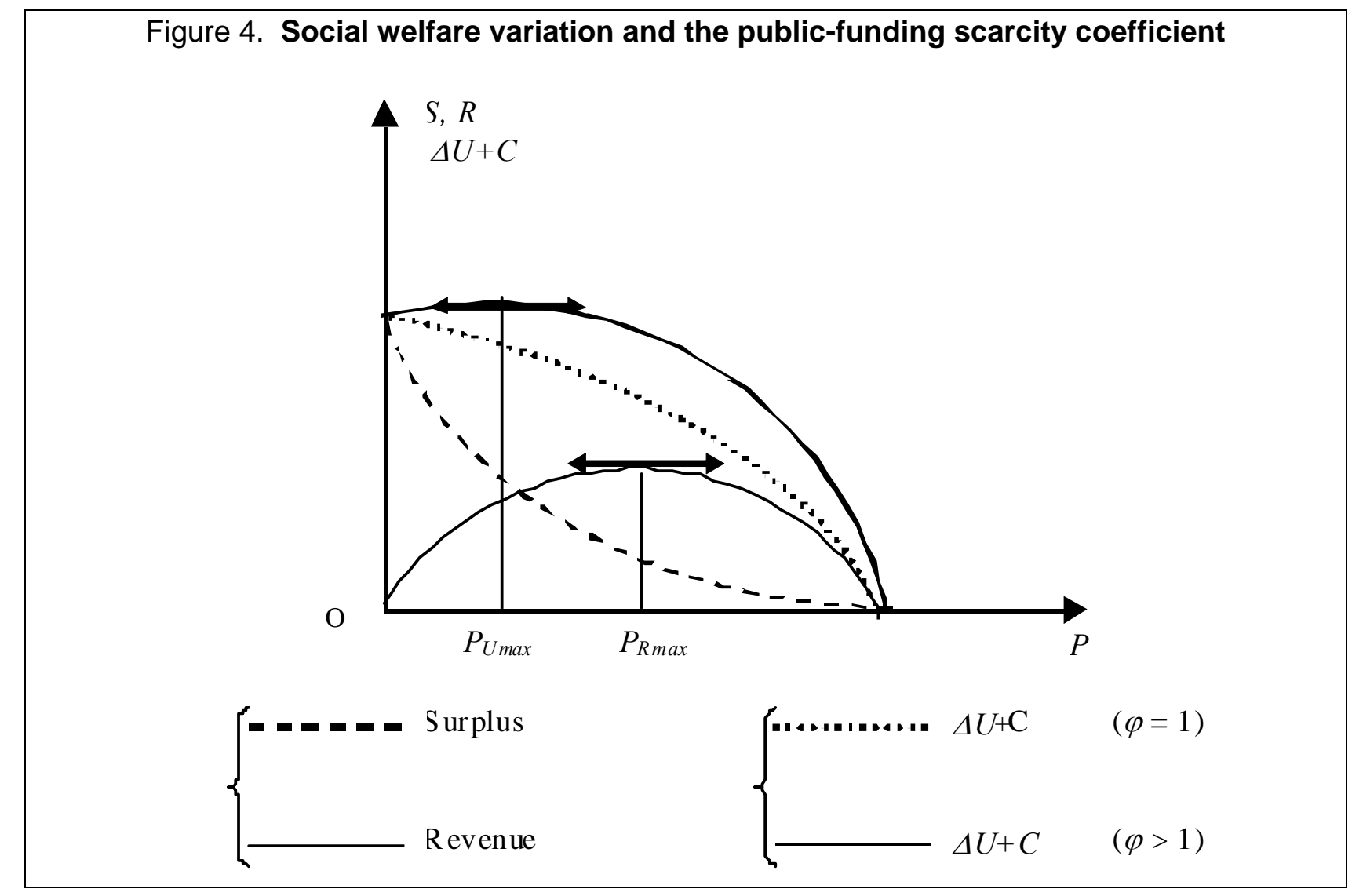

The optimal toll, in that it maximises the net present value of a project that has been approved, is therefore a function of the public-funding scarcity coefficient, which can readily be shown to be an increasing function that tends to $p_{R \max }$ when $\varphi$ increases but remains below it.

The economic interpretation of this result is fairly predictable: in the case of franchised infrastructure, it is in the public interest for the franchisor to remain in charge of tolls, since the socially optimal toll is lower than the one that maximises revenue. However, the more active the public-funding scarcity constraint, the higher it will be.

We shall see, however, that the problem can be viewed in markedly different terms when the rationale shifts from that of an individual project to a whole programme of projects, which must be optimised subject to budget constraint.

\section{From project optimisation to an "optimal programming toll" $\left(p_{o p}\right)$}

Figure 1, described in paragraph 2, suggests that ranking investments in decreasing order of financial returns, or in optimal order, produces a relative welfare gain compared with ranking by 
socio-economic returns, and the more active the budgetary constraint, the greater the gain will be. This raises the question of optimal pricing, not as addressed in the previous paragraph, i.e. pricing that maximises the socio-economic NPV of a specific project, but pricing that maximises the socio-economic NPV of a whole programme of projects subject to budget constraint. It is conceivable for instance that, for a given budgetary constraint, pricing that maximises revenue provides scope to make less use of subsidy and hence implement more projects than with pricing that maximises the NPV of each project.

To express the funding constraint, we recall, the level of subsidy as defined in paragraph 4 is as follows:

$$
S u b=C-R=C-d_{0 \cdot p}+\beta \cdot p^{2}
$$

With an available budget $\mathrm{B}$, a number of projects can be subsidised and it is then a question of working out a toll that optimises the net present value of the projects implemented subject to that constraint. This amounts to optimising the NPV per euro of public investment as shown earlier and, therefore, by using equations (5) and (8), determining the toll that maximises:

$$
\Delta U / S u b=\frac{-\varphi \cdot C+\frac{d_{0}{ }^{2}}{2 \beta}+(\varphi-1) \cdot d_{0} \cdot p+\beta \cdot\left(\frac{1}{2}-\varphi\right) \cdot p^{2}}{C-d_{0} \cdot p+\beta \cdot p^{2}}
$$

The derivative of this function is quite a complex calculation but can be considerably simplified to give:

$$
\frac{d(\Delta U / S u b)}{d p}=\frac{d_{0}{ }^{3}-2 C \cdot \beta \cdot d_{0}+2\left(C \cdot \beta^{2}-\beta \cdot d_{0}{ }^{2}\right) \cdot p+\beta^{2} \cdot d_{0} \cdot p^{2}}{\left(C-d_{0} \cdot p+\beta \cdot p^{2}\right)^{2}}
$$

Surprisingly, this equation shows that the public-funding scarcity coefficient $\varphi$ has vanished, meaning that the optimal programming toll does not depend on $\varphi$.

This is because the numerator, a second order polynomial in $p$, has two real roots. One is the value $d_{0} / \beta$ which is a trivial root and corresponds to the level of toll at which demand vanishes (like revenue and the user surplus, as shown in Figure 3 ). The other is a value obviously lower than $d_{0} / \beta$ which is the "optimal programming toll", denoted as $p_{o p}$, which optimises the social returns to the investment programme subject to a public funding constraint:

$$
p_{o p}=\frac{d_{0}}{\beta}\left(1-\frac{2 C \cdot \beta}{d_{0}^{2}}\right)
$$

To verify that this toll is lower than or equal to one that maximises revenue $\left(d_{0} / 2 \beta\right)$, we can put in the maximum revenue value $\left(d_{0}^{2} / 4 \beta\right)$ denoted as $R_{\max }$ and the corresponding subsidy value denoted as $S_{\min }$, which is therefore the minimum subsidy equal to $\left(C-R_{\max }\right)$. Equation (11) then becomes:

$$
p_{o p}=\frac{d_{0}}{2 \beta}\left(1-\frac{S_{\min }}{R_{\max }}\right)
$$


Interpreting this $p_{o p}$ using equations (11) and (12) provides valuable insights, some of which can be developed further.

\section{Properties of the optimal programming toll $\left(p_{o p}\right)$ and the PPP contract}

The most significant result produced by equation (11) is of course the independence of $p_{o p}$ in relation to the public-funding scarcity coefficient, unlike $p_{\text {Umax }}$ (equation 7 ). This optimal programming toll depends only on the cost of the project and the parameters characterising the demand function.

This result, formalised according to equation (12), can be interpreted in terms of the project's financial efficiency: when this is higher, with maximum revenue covering a large share of the costs, it is socially beneficial to close the gap between the optimal programming toll and the maximum revenue toll. If maximum revenue is higher than costs, the subsidy is zero and $p_{o p}$ becomes $p_{\text {Rmax }}$

In this case, a franchise contract between government and operator does not require a specific clause on tolls, even if users need to be protected from excessive charges, because it is not in the operator's interest to charge tolls exceeding $p_{R \max }$. On the other hand, the question does arise as to how any surplus should be shared out between franchisor and franchisee.

Conversely, when the operation's financial rate of return is low, the minimum subsidy takes on greater importance and, if it reaches the maximum revenue level, the $p_{o p}$ is zero. In this case, a toll does not bring any welfare gains and the scenario is typically that of a partnership contract as defined under French law (Order 2004-559 on Partnership Contracts), such as those used for toll-free stretches of motorway.

Equation (12) even suggests a specific rule: toll-free infrastructure (possibly based on a partnership contract) would be the right solution whenever the maximum discounted revenue fails to cover at least half of the discounted cost.

So there are three possible scenarios, depending on the financial efficiency of the projects under consideration:

1. When the minimum subsidy is at least equal to the maximum revenue, the optimal programming toll is zero. Whatever the toll, the revenue cannot cover over half of the cost. If the project is nevertheless eligible for the programme, it is because its $\mathrm{NPV/subsidy} \mathrm{ratio} \mathrm{is} \mathrm{relatively} \mathrm{high,} \mathrm{which} \mathrm{may} \mathrm{stem} \mathrm{from} \mathrm{various} \mathrm{factors,} \mathrm{such} \mathrm{as} \mathrm{major}$ environmental benefits or an overweighted user surplus justified by a redistribution policy. Examples include the so-called "territorial development" motorway projects, such as the work to bring up to motorway standard France's N88 highway between Toulouse and Saint Etienne. It is worth noting in this particular case that the involvement of a private partner in the building of future stretches of the motorway is indeed being envisaged on the basis of a partnership contract.

2. When a subsidy is necessary but lower than the maximum revenue, the optimal programming toll is positive but lower than the revenue-maximising toll. It should be set by government at the level defined by equation (11).

3. When the maximum revenue is sufficient to cover costs, equation (12) shows that the optimal programming toll "hits" the revenue-maximising toll. It would not be in the 
interests of either government or operator (statutory agency or franchisee) to go beyond that. That would mean a system in which operators were free to set tolls at their own discretion. The question arises, however, of how profits are split between franchisor and franchisee, as soon as revenue exceeds cost (which already includes interest on the franchisee's capital). The answer does of course affect the social welfare function if a public-funding scarcity coefficient is used.

It is clear from equation (11) what makes a project fall into one of these three categories. The first scenario covers cases with relatively low demand $d_{0}$, or high costs. These may include upland routes such as the N88 mentioned earlier, which runs through the Auvergne region. There may also be a high $\beta$ factor, meaning demand that is highly toll-sensitive, and roads for which the alternative route is toll-free but attractive.

The third scenario is quite the opposite, particularly when the alternative is a tolled or not very attractive route, in which case the $\beta$ factor is low. This has been observed on the AnnecyGeneva motorway franchise, where the successful bid was subsidy-free: the alternative route was either a long trip on a toll motorway, or a relatively dissuasive mountain road. The second scenario obviously falls between the other two and corresponds to many of today's potential projects, i.e. those with a higher immediate rate of return than the official discounted rate (currently $4 \%$ in France).

\section{Orders of magnitude in a case-study}

To flesh out what we have just seen with some figures and identify some orders of magnitude in a practical case-study, we shall use reference data from the SIMCALECO model developed at the LET (Chevasson, 2007) to test all the implications for the economic calculation of trade-offs used in the official evaluation methods.

This model reconstitutes all the calculations laid down in the Guideline "on the economic evaluation methods used for major transport infrastructure projects" (French Ministry of Public Works, 2004) in the case of motorway projects. It gives the calculations for the values of some 140 parameters required in such evaluations, the infrastructure characteristics in a benchmark scenario being as follows: a $90 \mathrm{~km}$ stretch of motorway to extend an existing $110 \mathrm{~km}$-long road which, prior to the motorway opening, carries 12000 vehicles a day; the investment amounts to $€ 400$ million while the current operating cost is $€ 200$ million, giving a total discounted cost of $€ 600$ million (for $C$ above); the initial toll is close to the average toll charged on the network franchised in 2005 (€0.066 per vehicle/km for private cars); the traffic split between road and franchised motorway is simulated with a LOGIT model.

This information gives a relatively high ERR of $21 \%$, but a low IRR of $5.1 \%$, which assumes a subsidy of $31 \%$ of the total discounted cost to take the IRR up to $10 \%$ for the operator. These are the orders of magnitude we are looking for in our analysis, together with some numerical values for the parameters.

We accordingly need to calibrate our demand function to obtain at best the traffic and revenues produced by the SIMCALECO model when the toll is varied. As the demand function is stylised in linear form, it can be suitably adjusted to the data in the benchmark scenario by selecting:

$$
d_{0}=10000 \text { million vehicle/kilometres (in automobile } \mathrm{v} / \mathrm{km} \text { equivalents) and }
$$


$\mathrm{d}_{0} / \beta=0.25$ euros (kilometre toll at which there is no more traffic).

These few values suffice to draw up the theoretical figures above with orders of magnitude representing specific scenarios. Thus Figure 4 becomes Figure 5 below. The social welfare variation is shown with three values for the public-funding scarcity coefficient (1, 1.4 and 1.8).

The problem here is the optimal toll for a single project and for the three values of $\varphi$ under consideration; it is clear that the toll that optimises the social welfare variation increases with this coefficient, as established with equation (7) and shown in Figure 6 below.

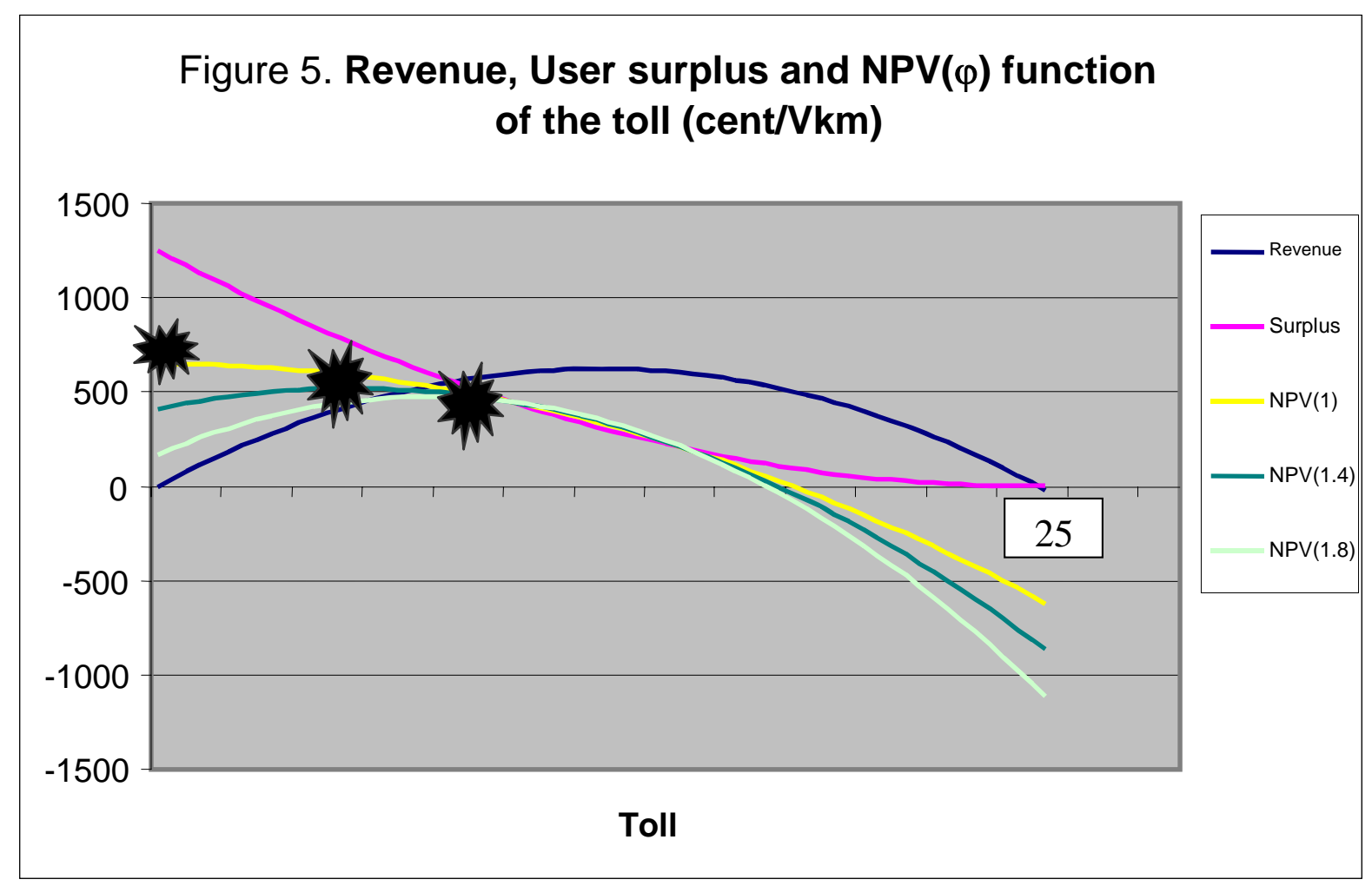

Moving on to the problem of the optimal programming toll, we obtain the same results from maximising the function $\Delta U / S u b$ with Figure 6 , clearly confirming that variations in $\varphi$ obviously affect the level of $\Delta U$, which is perfectly consistent with the fact that the project is making a loss: the higher $\varphi$ is, the heavier the loss for $\Delta U$. The figure also confirms the optimal programming analysis set out in paragraph 5 , namely that variations in the public-funding scarcity coefficient have no impact on the level of optimal programming toll, as shown in equation (12). 


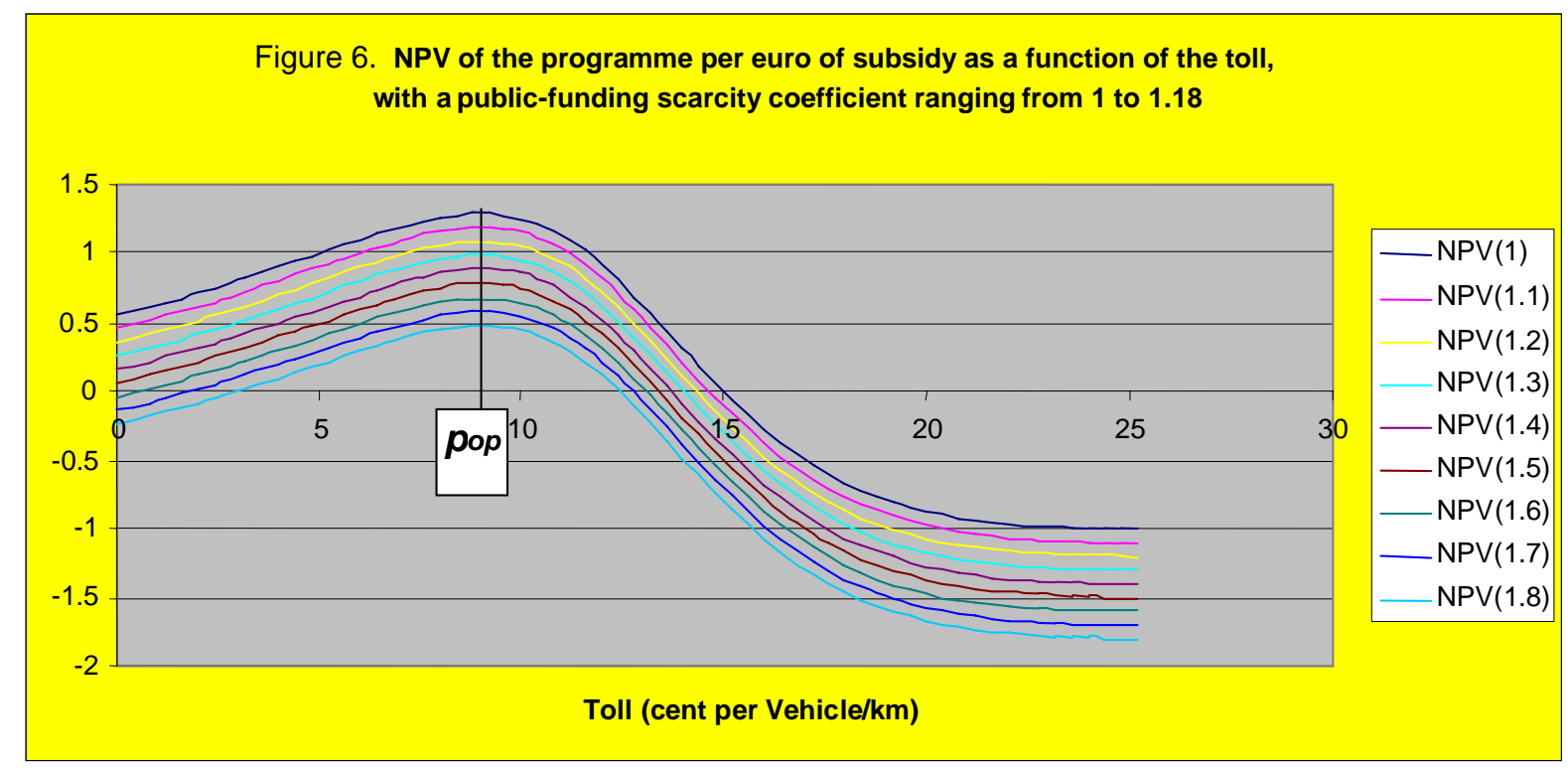

Moreover, we can identify the three optimal tolls mentioned above as a function of $\varphi$. It is worth noting that, while the toll that optimises a programme's NPV is never higher than the toll that optimises revenue, as we have shown, it may be lower than the toll that optimises the NPV of a specific project.

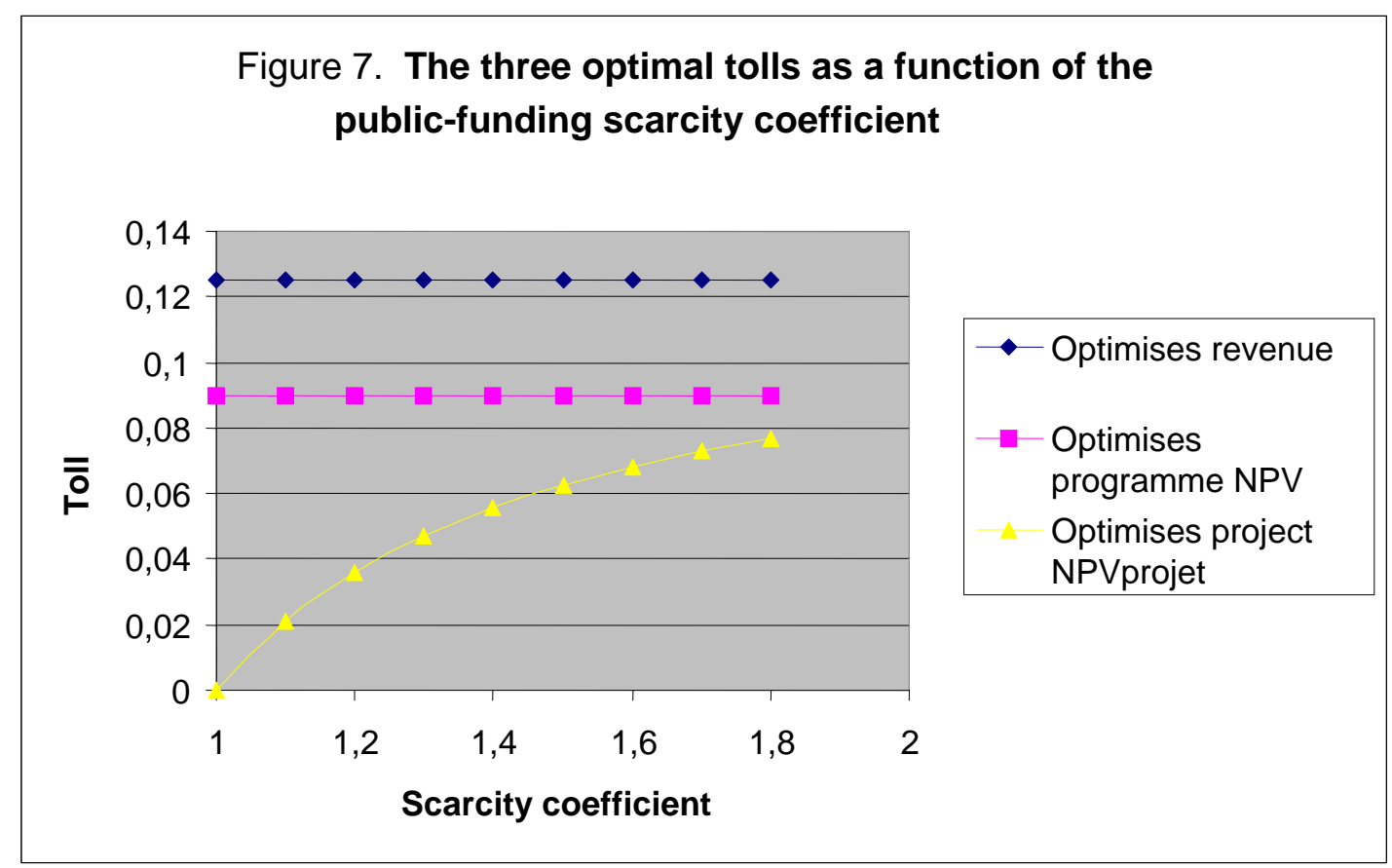

The main advantage of this series of graphs is that they give some orders of magnitude in an investment scenario that quite closely resembles that of an "average" motorway. For instance they show that, taking a scarcity coefficient of 1.3 as now recommended in France (Commissariat Général du Plan, 2005), the optimal project toll should be around $€ 0.05$ per v/km. However, the optimal programming toll should be around €0.09, whereas in practice it is below €0.07. For an 
unsubsidised project such as those discussed here, the $p_{o p}$ should be around $€ 0.125$, i.e. far higher.

All of this needs to be refined; for instance, we have made a somewhat bold assumption in differentiating between, on the one hand, the marginal social cost that would be internalised by a charge and, on the other, a user contribution towards funding the investment in the form of a toll. Further confirmation is needed. Nevertheless, we have suggested a pricing principle, for the optimal user/taxpayer mix, which implies distinguishing between various forms of partnership on the basis of a project's economic performance, in addition to the coherence that must be achieved between investment options, their evaluation and their funding formula.

In the three cases of optimal pricing that we have seen, i.e. no toll, a regulated toll and a freely set toll, the partnership contract must be given a different content. It should be noted that the use of private financing is not ruled out in any of these cases. At the ECMT's $16^{\text {th }}$ Symposium (Bonnafous, 2005), we had an opportunity to analyse the conditions under which the use of PPPs could reduce the burden on public spending and these conditions can only be improved by optimised tolls.

Lastly, it should be noted that under the very unusual circumstances of the economic and financial crisis we are currently experiencing, the convenience of public spending would seem to be of only a very fleeting nature. Consequently, the need to ensure that this spending creates more value than it destroys must obviously remain a key priority.

\section{- Acknowledgements}

The General Secretariat of the International Transport Forum is gratefully acknowledged for authorising the use of the most part of the invited paper I presented during the Forum 2009 ( entitled "The programming and optimal pricing of infrastructure in PPPs”, Leipzig, 26-29 Mai).

\section{BIBLIOGRAPHY}

ABRAHAM C. (2008), « Le recours au péage est-il économiquement condamnable ? », Working paper, $14 \mathrm{p}$.

ABRAHAM C. \& LAURE A. (1959) « Etude des programmes d'investissement routiers », Annales des Ponts et Chaussées, November-December.

BAUMOL W. \& QUANDT R. (1965), « Investment and Discount Rates Under capital Rationing, A Programming Approach », The Economic Journal, 75(298), pp.317-329.

BERTONECHE M., LANGOHR H. (1977), « Le choix des investissements en situation de rationnement de capital. Comparaison des solutions fournies par différents modèles théoriques», Revue Economique, 28(5). 
BLOY E., BONNAFOUS A, CUSSET J-M, GERARDIN B. (1976), Evaluer la politique des transports, Economica / Presse Universitaires de Lyon.

BOITEUX M. (1956)"Sur la gestion des monopoles publics astreints à l'équilibre budgétaire", Econometrica, 24 (1).

BONNAFOUS A., (2002), « Les infrastructures de transport et la logique financière du partenariat public-privé : quelques paradoxes », Revue Française d'Economie, 17(1).

BONNAFOUS A. \& JENSEN P. (2005), « Ranking Transport Projects by their Socio-economic Value or Financial Interest Rate of Return? », Transport Policy, 12, pp.131-136.

BONNAFOUS A., (2005), Infrastructure Funding and Public-Private Partnerships, ECMT's $16^{\text {th }}$ International Symposium, Budapest , 29-31 October, OECD Publications 2005, pp.193210.

CHEVASSON G. (2007), « L'influence relative des différentes valeurs tutélaires : un étude par la sensibilité des indicateurs socio-économiques », in « Le calcul économique dans le processus de choix collectif des investissements de transport », dir. Joêl Maurice et Yves Crozet, Economica, pp.191-220.

COMMISSARIAT GENERAL DU PLAN (1996), Transports : pour un meilleur choix des investissements, M. Boiteux (prés.), Paris : La Documentation Française.

COMMISSARIAT GENERAL DU PLAN (1997), Transports : le prix d'une stratégie, tome 1, A. Bonnafous (prés.), Rapporteurs D. Bureau, J.P. Puig, La Documentation Française.

COMMISSARIAT GENERAL DU PLAN (2001), Transports : choix des investissements et coût des nuisances, M. Boiteux (prés.), Rapporteur L. Baumstark, La Documentation Française.

COMMISSARIAT GENERAL DU PLAN (2005), Révision du taux d'actualisation des investissements publics, D. Lebègue (prés.), Paris : La Documentation Française.

DE PALMA A., LINDSEY R. \& PROOST S. (2007), Investment and the use of tax and toll revenues in the transport sector, Research in Transportation Economics, Vol. 19.

DESRIEUX C. (2006), Le rôle de l'autorité publique dans la gestion des services publics locaux : Une approche par la théorie des contrats incomplets, Revue économique, 57 (3).

Dupuit J., (1844), « De la mesure de l'utilité des travaux publics », Annales des Ponts et Chaussées, 2e série, pp. 332-375.

DupuIT J., (1849), « De l'influence des péages sur l'utilité des voies de communication », Annales des Ponts et Chaussées,2e série, pp. 170-248

HART O. (2003), « Incomplete Contracts and Public Ownership: Remarks, and an Application to Public-Private Partnerships », The Economic Journal, 113 (486).

HAYASHI Y. \& MORISUGI H. (2000), « International comparison of background concept and methodology of transportation project appraisal », Transport Policy, 7 (1). 
LAFFONT J.J. ET TIROLE J. (1993), A Theory of Incentives in Procurement and Regulation, MIT Press.

LESOURNE J. (1972), Le calcul économique : théorie et application, Dunod, 459 p. .(2006), « Le cofinancement usager-contribuable et le partenariat public-privé changent les termes de l'évaluation des programmes d'investissement public », Economie et Prévision, 4-5 (175176).

MAURICE J., QUINET E. \& SAUVANT A., (2006), « Optimisation et décentralisation des programmes d'investissements de transport », Economie et Prévision, 4-5 (175-176).

MINISTRY OF PUBLIC WORKS, FRANCE, (2004 and 2005), « Instruction cadre relative aux méthodes d'évaluation économique des grands projets d'infrastructures de transport », 25 March 2004 (updated 27 May 2005).

PONTI M. and ZECCA E. (2007), « The role of budgetary constraints on cost-benefits analysis of transport infrastructure investments and on environmental taxation $», 11^{\text {th }}$ WCTR, Berkeley, 24-26 June.

QUINET E. (2000), « Evaluation methodologies of transportation projects in France », Transport Policy, 7(1).

ROY, W. (2005), "Evaluation des programmes d'infrastructure: Ordre optimal de réalisation sous contrainte financière", LET working paper (http://halshs.archives-ouvertes.fr/halshs$\underline{00003971)}$. 